\title{
Reporting of Objective Color Measurements
}

\author{
Raymond G. McGuire \\ U.S. Department of Agriculture-Agricultural Research Service, Subtropical Horticulture \\ Research Station, 13601 Old Cutler Road, Miami, FL 33158
}

\begin{abstract}
The analysis of color is frequently an important consideration when determining the efficacy of a variety of postharvest treatments. Consumers can easily be influenced by preconceived ideas of how a particular fruit or vegetable should appear, and marketers often attempt to improve upon what nature has painted. In spite of the significance of color in our work, however, many researchers continue to analyze this characteristic inappropriately. The confusion that results is unnecessary; easily computed and readily understood measures are available to clarify color descriptions for researchers and marketers alike.
\end{abstract}

Specifically, many scientists in the field of market quality, who are using instruments such as the Hunter colorimeter (Hunter Assoc., Reston, Va.) and various Minolta chroma meters (Minolta, Ramsey, N.J.), analyze and publish a set of Cartesian coordinates generated directly by the instrument. These coordinates pinpoint the measured color in a three-dimensional color space. However, without further manipulation, this information does not provide an indication of hue and chroma-aspects of color that are intuitively understood by those in the marketing chain from producer to consumer.

These aspects of color are addressed directly in the color chart-based Munsell notation that specifies the elements of perceived color as value (lightness, from black to white on a scale of 0 to 10), chroma (degree of departure from gray toward pure chromatic color), and hue (red, orange, yellow, green, etc.). In contrast, the instrumentally obtained coordinates, CIE 1931 (Y, x, y) or CIE $1976\left(\mathrm{~L}^{*}, \mathrm{a}^{*}, \mathrm{~b}^{*}\right)$, provide information on lightness directly but require some computation to yield explicit measures of chroma and hue (Hunter and Harold, 1987). CIE refers to the Commission Internationale de l'Eclairage (International Commission on Illumination).

In the CIE $1976\left(L^{*}, a^{*}, b^{*}\right)$ color space, abbreviated CIELAB, the lightness coefficient, $\mathrm{L}^{*}$, ranges from black $=0$ to white

Received for publication 1.5 June 1992. Accepted for publication 17 Aug. 1992. The cost of publishing this paper was defrayed in part by the payment of page charges. Under postal regulations, this paper therefore must be hereby marked $a d$ vertisement solely to indicate this fact.
$=100$ and is roughly analogous to the Munsell value scale times 10 . For any measured color of lightness, $\mathrm{L}^{*}$, the coordinates $\left(\mathrm{a}^{*}\right.$, $\left.b^{*}\right)$ locate the color on a rectangular-coordinate grid perpendicular to the $\mathrm{L}^{*}$ axis at $\mathrm{L}^{*}$. The color at the grid origin $\left(\mathrm{a}^{*}=0\right.$, $\mathrm{b}^{*}=0$ ) is achromatic (gray). On the horizontal axis, positive $a^{*}$ indicates a hue of red-purple; negative $\mathrm{a}^{*}$, of bluish-green. On the vertical axis, positive $b^{*}$ indicates yellow and negative $b^{*}$ blue (Fig. 1).

Many researchers publish their data in either the CIELAB (L*, $\left.a^{*}, b^{*}\right)$ scale or in the older Hunter $\left(\mathrm{L}_{\mathrm{L}}, \mathrm{a}_{\mathrm{L}}, \mathrm{b}_{\mathrm{L}}\right)$ scale just as the numbers are printed out by the various colormeasuring devices. Although the measure of a color's lightness, L, is correctly reported without further manipulation, $\mathrm{a}$ and $\mathrm{b}$ are merely coordinates that indirectly reflect hue and chroma but are difficult to interpret separately. More importantly, these coordinates are not independent variables (Francis, 1980). An inappropriate statistical analysis performed on these color components may appear to yield significant results, but what would these results signify?

Consider three types of heat treatment applied to grapefruits to test their tolerance to fruit fly eradication procedures. These treatments might include a comparison of immersions in moist or dry heated air or in hot water. From an analysis of variance and means separation, fruits from treatments 2 and 3 are said to be significantly redder (CIELAB a*) than fruits of treatment 1 (Table 1). At the same time, fruits of treatment 3 are said to be significantly less yellow (CIELAB $b^{*}$ ) than those of the other two treatments. Fruits of treatment 3 are also significantly darker (CIELAB L*) than those of treatments 1 and 2. From these numbers alone can anything really be said about the visually perceived color differences among these fruits? With an appropriate color wheel one could plot the $a^{*}$ and $b^{*}$ values and see the difference in hues, but such a device is usually not at hand. Instead, the data are often ignored as nearly senseless. The superficial reporting of these hue coordinates also fails to note the intensity of color, which can often change after postharvest treatment.

The proper quantification of tristimulus colorimetry data is based upon trigonometric functions (Hunter, 1942). A color wheel subtends $360^{\circ}$, with red-purple traditionally placed at the far right (or at an angle of $0^{\circ}$ ); yellow, bluish-green, and blue follow counterclockwise at $90^{\circ}, 180^{\circ}$, and $270^{\circ}$, respectively (Fig. 1). Plotting the hue coordinates from Table 1 identifies the grapefruit as being shades of yellow. Those of treatment 1 are indeed greener and possibly less ripe than the fruit of the other two treatments, as was surmised by the statistical analysis of CIE$\mathrm{LAB} \mathrm{a}^{*}$. But what is impossible to deduce from the analyses of $a^{*}$ and $b^{*}$ is that fruit of treatments 2 and 3 are of the same hue; the difference between the two is in lightness and chroma.

A more appropriate measure of color can be obtained from the calculation of hue angle $\left(\mathrm{h}^{\circ}\right)$ and Chroma $\mathrm{C}^{*}$, an index somewhat analogous to color saturation or intensity (Hunter, 1942; Little, 1975). These may be calculated from $a^{*}$ and $b^{*}$ or, on newer Minolta instruments, may be read directly. Chroma $\mathrm{C}^{*}$ is calculated as $\left(\mathrm{a}^{*^{2}}+\mathrm{b}^{*^{2}}\right)^{1 / 2}$ and represents the hypotenuse of a right triangle created by joining points $(0,0),\left(a^{*}\right.$, $\left.\mathrm{b}^{*}\right)$, and $\left(\mathrm{a}^{*}, 0\right)$. Hue angle may be defined as the angle between the hypotenuse and $0^{\circ}$ on the $a^{*}$ (bluish-green/red-purple) axis; $h$ is calculated from the arctangent of $b^{*} / a^{*}$. Arctangent, however, assumes positive values in the first and third and negative values in the second and fourth quadrants. For a useful interpretation, $h^{\circ}$ should remain positive between $0^{\circ}$ and $360^{\circ}$ of the color sheel. The following program for use in SAS (1985) accomplishes this requirement between $0^{\circ}$ and $360^{\circ}$ and is especially useful for determining color differences in fruit that ripen from green to either yellow or shades of red. CIELAB $\mathrm{L}^{*}, \mathrm{a}^{*}$, and $\mathrm{b}^{*}$ values are input.

Table 1, Analysis of grapefruit peel color after three heat treatments for quarantine control of Caribbean fruit flies.

\begin{tabular}{lrrrrr}
\hline \hline \multirow{2}{*}{$\begin{array}{l}\text { Treat- } \\
\text { ment }\end{array}$} & \multicolumn{4}{c}{ Color characteristics } \\
\cline { 2 - 6 } & $\mathrm{L}^{*} \mathrm{c}$ & \multicolumn{1}{c}{$\mathrm{a}^{*}$} & $\mathrm{~b}^{*}$ & $\mathrm{C}^{*}$ & $\mathrm{~h}^{\circ}$ \\
\hline 1 & $76.5 \mathrm{a}$ & $-2.0 \mathrm{a}$ & $56.0 \mathrm{a}$ & $56.0 \mathrm{a}$ & $92.0 \mathrm{a}$ \\
2 & $74.4 \mathrm{a}$ & $2.0 \mathrm{~b}$ & $56.0 \mathrm{a}$ & $56.0 \mathrm{a}$ & $88.0 \mathrm{~b}$ \\
3 & $63.2 \mathrm{~b}$ & $1.2 \mathrm{~b}$ & $34.0 \mathrm{~b}$ & $34.0 \mathrm{~b}$ & $88.0 \mathrm{~b}$ \\
\hline
\end{tabular}

${ }^{2}$ Means of 90 fruit per treatment using a Minolta chroma meter CR-200 measuring in CIELAB. L* $=$ lightness, $\mathrm{a}^{*}=$ bluish-green/red-purple hue component, $\mathrm{b}^{*}=$ yellow/blue hue component, $\mathrm{C}^{*}$ $\left[\left(a^{* 2}+b^{* 2}\right)^{1 / 2}\right]=$ chroma, $h^{0}$ (from arctangent $\left.\mathrm{b}^{*} / \mathrm{a}^{*}\right)=$ hue angle $\left(0^{\circ}=\right.$ red-purple, $90^{\circ}=$ yellow, $180^{\circ}=$ bluish-green, $270^{\circ}=$ blue). yean separation at $P=0.05$ according to the Ryan-Einot-Gabriel-Welsh multiple F test. 


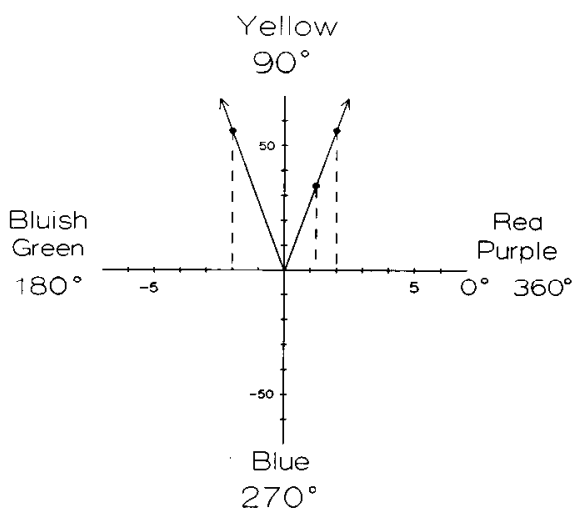

Fig. 1. Representation of peel hue affected by heat quarantine treatments of grapefruit. ClE$\mathrm{LAB} \mathrm{a}^{*}$ and $\mathrm{b}^{*}$ values are plotted on horizontal and vertical axes, respectively. Treatment 1 , $(-2,56)$; treatment $2,(2,56)$; treatment 3 , $(1.2,34)$. The scale is compressed vertically for clarity.

DATA COLOR;

INPUT TRT L a b;

$\mathrm{C}=\operatorname{SQRT}((\mathrm{a} \times \mathrm{a})+(\mathrm{b} \times \mathrm{b}))$;

THETA $=(\operatorname{ATAN}(\mathrm{b} / \mathrm{a}) / 6.2832) \times 360$;

IF $a>0$ AND $b>=0$ THEN $h=$ THETA;

IF $a<0$ AND $b>=0$ THEN $h=180+$ THETA

IF $a<0$ AND $b<0$ THEN $h=180+$ THETA;

IF $a>0$ AND $b<0$ THEN $h=360+$ THETA;

OUTPUT;

DROP a b THETA;

CARDS;

The calculation of $C^{*}$ is straightforward. However, because the SAS software is developed to compute trigonometric functions in radians rather than in degrees, a conversion for $h^{\circ}$ is preferable. The above program divides $b^{*}$ by $a^{*}$, takes the arctangent (in radians) of the remainder, divides this number by an approximation of $2 \pi$ (the number of radians equivalent to $360^{\circ}$ ), then multiplies this quotient by 360 to achieve an angle in degrees. Note that $a^{*} \neq 0$. The program then compensates for a location in the first, second, third, or fourth quadrant.

When the $a^{*}$ and $b^{*}$ data of Table 1 are converted to $\mathrm{C}^{*}$ and $\mathrm{h}^{\circ}$, they become the values in the fourth and fifth columns of Table 1, respectively. According to the guidebook for the Minolta chroma meter, when the color aspects of value, chroma, and hue angle are combined, fruit of these three treatments would be labeled vivid green-yellow, vivid orange-yellow, and dull orange-yellow, respectively. Naming the colors, however, would be unnecessary as long as all characteristics are listed.

This program for converting CIELAB $\mathrm{a}^{*}$ and $\mathrm{b}^{*}$ values into chroma and hue angle is not only applicable for fruits and vegetables that may ripen to any color between a pale green, such as pears $\left(\mathrm{L}^{*}, \mathrm{C}^{*}\right.$, and $\mathrm{h}^{\circ}$ values of $80.1,48.9$, and 153, respectively); yellow, such as grapefruits; and a dark red-purple, such as eggplants $(25.4,5.2$, and 2.5, respectively). The program also is suitable for delineating the blues and purples of such fruits as blueberries $(58.6,21.6,273)$ and grapes $(43.4,6.6,310)$. Translating $\mathrm{h}^{\circ}$ into an approximate idea of hue is simple when a single footnote in a table gives the cardinal points of the color wheel.

Many researchers, however, continue to report their tristimulus colorimetry data as "L, a, b" numbers without regard to how these values might be interpreted by their audience. Some instruments of the Minolta Corp. report color in both the CIELAB and the Hunter scales; the two scales are related but are not identical, and they should be identified. The instrument's illuminant $(\mathrm{C}$ or D65), calibration standard(s), and illuminant/viewing geometry (d/0 or $45 / 0$, for example) must also be mentioned. It is equally important after data acquisition to avoid inappropriate statistical analyses on the hue components $\mathrm{a}^{*}$ and $\mathrm{b}^{*}$ when chroma and hue angle should instead be computed and ana- lyzed. Most people are probably unaware of how easily color analysis may be more effectively applied. With the knowledge and tools now at their disposal, researchers should begin to consistently report all the data required to make an informed judgement of color analysis.

\section{Literature Cited}

Francis, F.J. 1980. Color quality evaluation of horticultural crops. HortScience 15:58-59.

Hunter, R.S. 1942. Photoelectric tristimulus colorimetry with three filters. NBS Circ. C 249, U.S. Dept. Commerce, Washington, D.C.

Hunter, R.S. and R. Harold. 1987. The measurement of appearance. 2nd ed. Wiley, New York.

Little, A.C. 1975. Off on a tangent. J. Food Sci. 40:410-411

SAS. 1985. SAS user's guide: Statistics. Version 5 ed. SAS Institute, Inc., Cary, N.C.

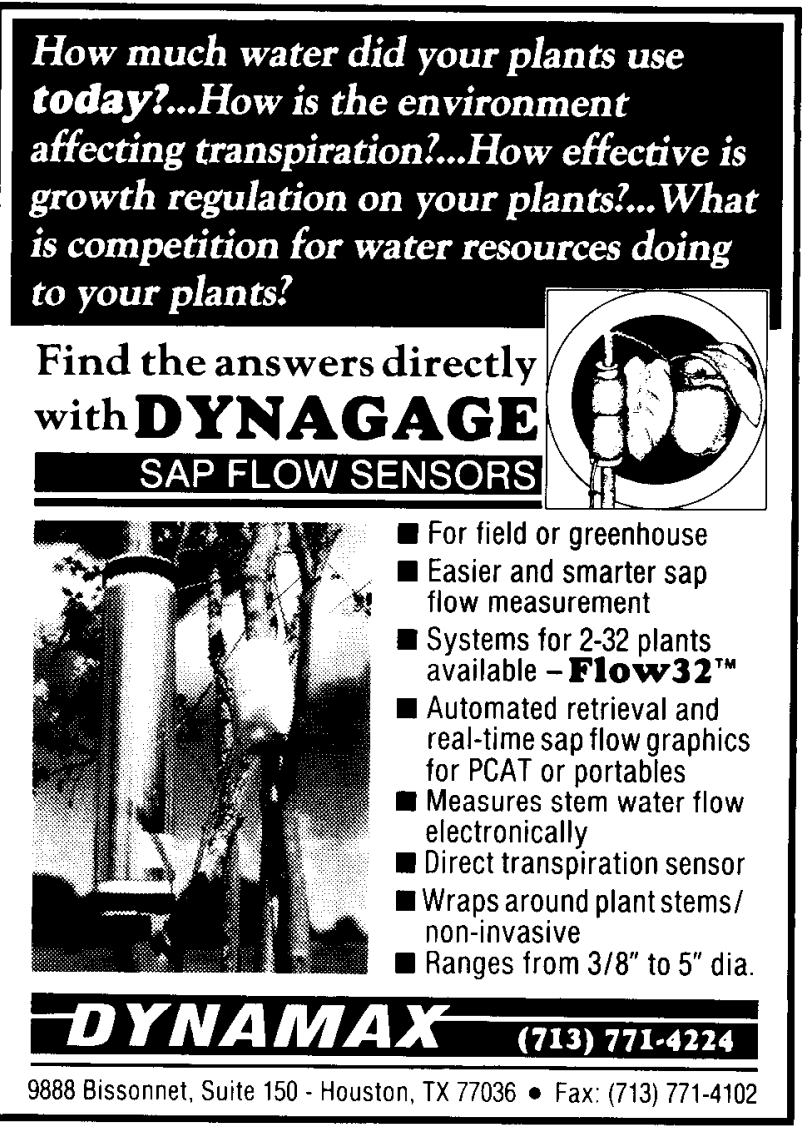

